\title{
IMPROVEMENT OF TRANSLAMINAR TOUGHNESS OF COMPOSITE MATERIALS THROUGH PSEUDO-DUCTILITY
}

\author{
A. Subramani*, P. Maimi and J. Costa \\ ${ }^{1}$ AMADE, Polytechnic School, Universitat de Girona, Campus Montilivi s/n, Girona 17071, Spain \\ *anbazhagan.subramani@udg.edu
}

Composite materials are notable for their high strength-to-weight ratio, but the inherent quasi-brittle nature of its constituents prevent the optimal use of the material. Fracture toughness in an elastic-plastic material is dominated by the crack tip plasticity leading to steady-state toughness that increases several times the initiation toughness. However, they are practically absent in composite materials, so the toughness contribution is largely due to work of separation (matrix cracking, fibre bridging and pull-out). Therefore, several research groups are trying to confer "ductile" behaviour to laminated composites in order to achieve increased notched strengths and more damage-tolerant designs. Several approaches have been shown to achieve pseudo-ductility. Most of them are based on combining low-strain materials (e.g. carbon fibre) with high-strain materials (e.g. glass fibre) either at a ply level or laminate level [1].

The objective of the current study is to numerically determine the influence of the parameters associated with describing pseudo-ductility on the translaminar toughness and notched strengths. Developed FE models use continuum mechanics based on homogenised linear elasticplastic material behaviour while the separation behaviour past the damage initiation is modelled by the cohesive law. Systematic investigation of non-dimensional material parameters and their influence was studied with Compact Tension (CT) specimens, followed by the notched strengths with Open-Hole $(\mathrm{OH})$ and Centre-Crack (CC) specimens. Results obtained illustrate,

- The improvement of pseudo-ductility on fracture toughness of CT specimens as illustrated in Figure 1 where the effect of pseudo-ductility (a) in the fracture toughness (b) is presented.

- The reduction of notch sensitivity factor on the nominal strength of $\mathrm{OH}$ and $\mathrm{CC}$ specimens [2].
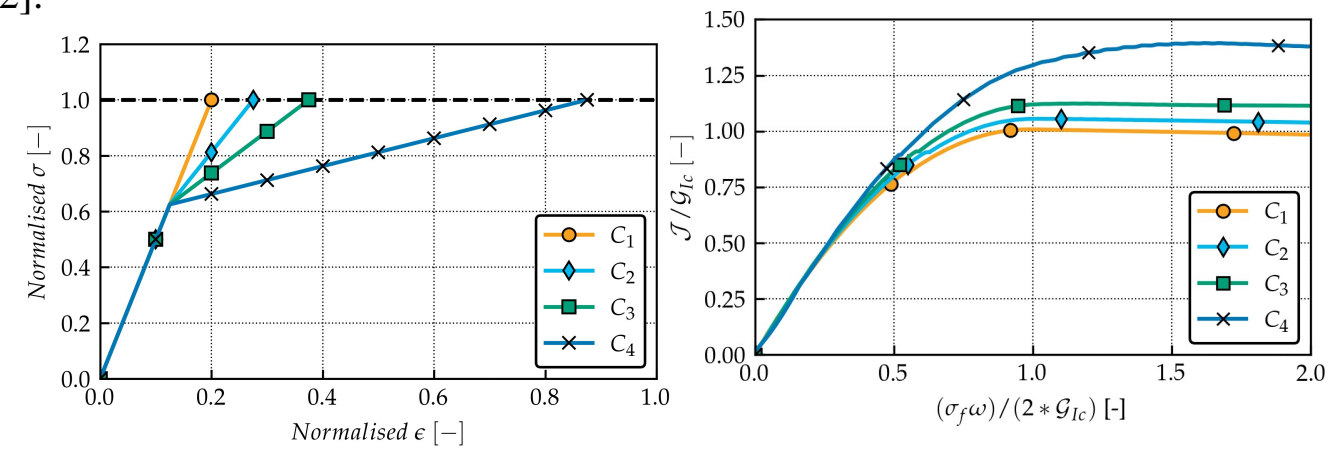

Figure 1. (a) Pseudo-ductile material behaviour considered. (b) Normalised fracture toughness.

\section{References}

[1] X.Wu, J.D. Fuller, M.L. Longana, M.R. Wisnom (2018), Composites Part A 111, 62-72. DOI: 10.1016/j.compositesa.2018.05.011

[2] P.Maimi, E.V. Gonzalez, N.Gascons, L.Ripoll (2013), Applied Mechanics Reviews, 65(2), 20802. DOI: $10.1115 / 1.4024163$ 